\title{
Abstract Teaching for a Concrete World: A Lesson from Plato
}

Peter Lindsay, Georgia State University

ABSTRACT This article argues that instructors should introduce students to abstract concepts only after they have provided concrete illustrations of them. The advantages of working from the concrete to the abstract are twofold: (1) students have an easier time conceptualizing abstractions from within a particular context, and (2) such a context provides them with a greater motivation to do so. In an effort to mirror the pedagogical approach I defend, I begin by reviewing the manner in which Plato introduces the concept of justice to his readers in Book I of the Republic. I then examine the common model of teaching abstract concepts, demonstrate how an effective alternative differs from this model, and review the education theories that support the alternative model.

We ought to begin from things known to us.

-Aristotle (Ethics, 1095b)

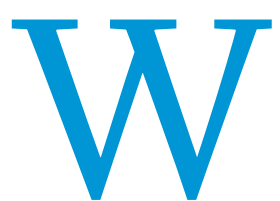

hen I think of difficult topics to teach in the field of political philosophy, few surpass Plato's theory of the forms. The idea that causes students particular problems is that the reality we perceive is only a concrete version of a higher, nonmaterial Truth-that although we perceive tables and chairs around us, such objects are merely manifestations of "tableness" and "chairness," ideas ("forms") that are themselves the reality. The particular pedagogical problem with this concept is that even when students rise to the conceptual challenge, they are hard pressed to see the sense-perceived world they inhabit as the unreal one. Like the essayist Edward Abbey, they suspect that if you threw a rock at a guy like Plato, he (like the rest of us) would duck, thereby exposing the deceit.

This conceptual reluctance is not surprising. Nothing about the manner in which students perceive the world leads them to Plato's conclusion (or, for that matter, to any idealist theory, such as Hegel's Spirit or Kant's noumena). Even putting aside the matter of whether abstract concepts are ontologically prior to the senseperceived world, they are certainly foreign to the everyday existence of most students. ${ }^{1}$ After all, individuals inhabit a world of things,

Peter Lindsay is an associate professor of political science and philosophy and the Director of the Center for Teaching and Learning at Georgia State University. He is the author of Creative Individualism: The Democratic Vision of C. B. Macpherson (SUNY, 1996) as well as articles on various topics in political theory. He can be reached at plindsay2@gsu.edu. not ideas. We see this fact most clearly in the youngest of them: ask a three-year-old how many carrots one would have by adding three carrots to two carrots, and he or she could probably tell you. You would not, however, have the same luck by asking what three plus two is. This difficulty makes sense: "three carrots" is something we can all wrap our heads around. But three? How exactly might we explain threeness? Even trying to define this concept in a noncircular manner presents a challenge.

So how should we teach students the foundational language of any body of knowledge? In the case of political science, how might we best introduce abstract concepts such as representation, social class, equality, rights, or democracy? The answer I explore here grows not simply out of my experiences teaching political philosophy, but also out of experiences I have had as the director of my university's teaching center observing classrooms across a wide array of disciplines. To the extent that all disciplines, from the social and natural sciences to business, law, and the humanities, involve the study of generalizable phenomena, the task of teaching abstract concepts is a shared classroom experience. So, too, I have found, is the method that teachers commonly employ to fulfill that task. I argue in the following that while there is something amiss with that method, correcting its central flaw involves a remarkably simple adjustment.

This argument is divided into three parts: (1) a review of the common model of teaching abstract concepts, (2) an exploration of an alternative approach, and (3) a discussion of why we should view that alternative as superior. I finish with a general thought about how this alternative speaks to an ideal that lies at the heart of education. Since I am a firm believer that the form of an argument should mirror its substance, I shall, as a prologue, briefly 
review what is perhaps the greatest, and certainly one of the earliest, examples of the alternative model, an example that takes us from Book VII of the Republic to Book I.

\section{PLATO'S JUSTICE}

Book I famously solves very little of the Republic's central question: What is justice? By the end of the book, most of the interlocutors are angry and no one is any the wiser, as Socrates has effectively undermined the three claims about justice made in turn by Cephalus, Polemarchus, and Thracymachus. Cephalus' claim (as formulated by Socrates) that justice is "speaking the truth and paying whatever debts one has incurred" (Plato 2004, 331C) is shown to be inadequate, because, as Socrates points out, "if a sane man lends weapons to a friend and then asks for them back when he is out of his mind, the friend shouldn't return them, and wouldn't be acting justly if he did. Nor should anyone be willing to tell the whole truth to someone who is out of his mind" (331c).

In similar fashion, Polemarchus' claim (as formulated by Simonides) that justice is "to give to each what is owed to him" (Plato 2004,331e) fails, Socrates points out, because there are clearly cases in which giving what is owed would not be just. For instance, to give what is owed might entail that a just man "harm those who are both bad and enemies" (335b). Yet because "it is never just to harm anyone" (335e)-because "people who are harmed must become more unjust" (335c)-such harm would clearly not be justice. interlocutors-is more than compensated by their newly acquired investment in discovering what those answers might be. Moreover, if the discussions of paying debts and keeping promises show more readily what justice is not, they also demonstrate vividly what is at stake. Students not only get a sense that examples of things are not things themselves, but they also see the sorts of things of which this particular thing-justice-consists.

\section{TEACHING ABSTRACTIONS: MODEL 1}

Book I offers a number of pedagogical insights. ${ }^{3}$ To illustrate those insights, let us put aside Plato for a moment and consider the common method of teaching abstract concepts. In introducing such concepts to students, instructors commonly take the following four steps: First, they write the concept on the board. Second, they offer a pithy definition of it (something to memorize for the test). Third, they explain what that pithy definition really means. Fourth, they offer a few examples to further clarify their explanation. The essential element of this pedagogical approach lies in its order-and so too does its central shortcoming.

First, note that every step is an effort to remedy the conceptual opacity of the previous one: the definition seeks to capture the word, the explanation seeks to clarify the definition, and the examples seek to concretize the explanation. Instead of each step preparing students for the following one, each is reduced to doing damage control for the preceding one. By starting with the for-

\section{By starting with the foreign and unfamiliar (the concept) and then working back to the familiar (the explanation with concrete examples), several things may have happened. Perhaps the most problematic among them is that in offering a term and a definition before students can understand its meaning, the instructor has invited what can best be described as cognitive paralysis-that sense of despair that makes whatever explanation the instructor then provides all the more difficult to follow.}

Both Polemarchus and Cephalus fail to understand justice, then, because they conceive it only as particular acts. ${ }^{2}$ In lacking an appreciation for the universal, both capture justice only partially; that is, they capture acts that could be just in certain contexts, but which are ultimately only examples of justice. What Socrates wants, however, is an understanding of justice that explains what makes any particular act a good (or bad) example of it. Examples are fine, but they do not tell us what justice is.

The discussion that follows in Books II through $\mathrm{X}$ is more general and abstract, as Plato-because examples do not sufficeforces his readers to think less of actions and more of concepts. Here, discussions of model cities and virtues such as courage and moderation predominate. What I consistently notice, however, is that while the reading can be slow and even tortuous, students are apt to stick it out to a far greater extent than they are in reading other slow and tortuous texts. Why? Because of Book I. For many reasons, not the least being Thracymachus' dramatic entrance and vitriolic attack on Socrates, Book I captivates students. Here they can find arguments about particular actions with examinations of whether those actions might constitute something of virtue. Whatever frustration students have with Plato's lack of answers-frustrations that mirror those of Socrates' eign and unfamiliar (the concept) and then working back to the familiar (the explanation with concrete examples), several things may have happened. Perhaps the most problematic among them is that in offering a term and a definition before students can understand its meaning, the instructor has invited what can best be described as cognitive paralysis - that sense of despair that makes whatever explanation the instructor then provides all the more difficult to follow. Definitions, after all, are cumbersome. (If you want to induce mass anxiety in your classroom, take a few minutes and read aloud from the glossary of your text.) Their purpose is to capture the essence of a concept in as general and succinct a form as possible. The task is analytic-capturing meaning with an economy of words-but certainly not pedagogical. At best, definitions can clarify a concept after someone has an incipient understanding of it. We should, therefore, certainly not conflate knowledge of a definition with an understanding of the concept it defines.

The problem here is not simply conceptual. Beyond invoking confusion, working back to the familiar instead of starting with it deprives students of their motivation to learn. Telling them, as Wikipedia-the source of all student knowledge-does, that justice is "the concept of moral rightness based on ethics, rationality, 
law, natural law, religion, fairness, or equity" hardly inspires devotees of political science. More commonly, this approach elicits the question: "Will this definition be on the test?" In this context, the question is not unreasonable; what other motivation do students have to commit this term to memory? And what motivation is there to do anything but commit it to memory?

Whereas Book I of the Republic reveals no definitive understanding of justice and so, as a lesson on this subject, must be considered incomplete, it runs afoul of neither pedagogical concern. The book avoids producing cognitive paralysis, because no abstraction (which might cause this condition) is ever offered-at least not by Plato.. Students are in a sense duped: they may believe that they are reading about what justice is, but instead, they are only considering particular cases of it-cases that require thought but present no forbidding conceptual hurdles. Moreover, because the cases are so clearly relevant to individuals' lives, the motivational issue is practically defined away: What student needs motivation to discuss the common moral experiences of his or her life? Perhaps it is cynical to say that narcissism is an excellent motivator. It is surely true, however, that motivation to learn is proportional to the degree that students can relate to the material. (I explore this claim in more depth in section IV.)

\section{TEACHING ABSTRACTIONS: MODEL 2}

With these thoughts in mind, let us think about what it would mean to invert the order of our four steps, providing us with the following chronology: first, the provision of examples; second, an explanation of what, conceptually, those examples share; third, the definition-like summing up of that concept; and fourth, the revealing of the word we use for the concept. Consider how this approach might look. Suppose I walk into a classroom and, in a seemingly random manner, begin talking about a recent personal (and regrettably true) experience: "The other day, I was pulled over and ticketed for speeding. Now, I was indeed exceeding the speed limit, but I was not exceeding the speed of traffic on the highway. In fact, on occasion, I was being passed by other cars."

At this point, I might ask, "What do you think?" (Notice that I do not ask "Was it fair or just that I was singled out?" I am trying to show the students what it would mean to answer that question, and so I cannot logically presuppose that ability in the demonstration. ${ }^{6}$ ) Imagine the conversation that might ensue:

Student: Well, but you did speed.

Professor: Yeah, but so did others, and they weren't treated in the same way.

Student: Yeah, but it would be impossible to stop everyone, and that isn't a reason to stop no one.

Professor: Well, might it be? I mean, if they're going to select people, what will determine who they select? If they can't come up with a good system, perhaps it wouldn't be a good idea to go after anyone.

At this point, I could nudge the conversation to an examination of how to select who is given a ticket from thousands of speeders:

Student: Okay, so what would a good system be?

Professor: Well, you thought it was okay that they pulled me overwhat made that system okay?

Particularly Astute Student: It was okay because you just happened to be coming along when the officer got there, and so were randomly chosen. Professor: What makes random selection okay?
Another Particularly Astute Student: It doesn't treat you differently on grounds that are irrelevant to the goal of ticketing-namely, highway safety.

Professor: What grounds would be irrelevant?

Student: Race, gender, political affiliation as inferred by bumper sticker or car model.

What we can see so far is a compelling and easy-to-follow story, especially for anyone who has ever been ticketed. We can imagine the gist of the remainder of the discussion: I slowly bring the conversation around to an agreement that differential treatment before the law is only justifiable when the differences between people are morally salient to the law. Notice that even in the context of the conversation, the statement "differential treatment before the law is only justifiable when the differences between people are morally salient to the law" is not all that easy to grasp. Imagine what would have happened if I had begun the class with that statement-that is, if I had presented it without the context of my speeding story and the ensuing discussion. I would argue that because I did not adopt that approach but chose instead to hang the concept on a meaningful narrative, I accomplished two objectives: I gave students an understanding of what justice is concerned with, and I gave them a reason to want to understand what it is concerned with. With that motivation and that conceptual preparation, an understanding that "differential treatment before the law is only justifiable when the differences between people are morally salient to the law" becomes possible.

Also possible is what follows from that understanding-namely, a discussion of how this way of looking at treatment before the law is what "justice" is all about. Slowly, then, the conversation that began with a concrete case has moved to an abstract concept that informs our thinking about the case. In moving from the concrete to the abstract, I have used the students' own understanding at each step as a springboard to the next one. Movement is thus driven by understanding rather than confusion, stemming not from students' needs, but from their abilities.

How does this conversation end? It ends in the same manner that our first model began: with an attempt to capture the concept's meaning in a few words and by writing the word we have for the concept on the board. If this last step appears to be an afterthought, it is. The primary concern, after all, is with the meaning of concepts, not the names we have for them. We are not concerned that students be able to name or define justice-as in, being able to answer the question: "What is the virtue concerned with treatment of citizens before the law?" or being able to write "the virtue concerned with treatment of citizens before the law" in response to the question, "What is justice?" (Would we really presume that the student who could answer either question understood the concept in a meaningful sense?) What we want is for them to understand what it means to have such a virtue and what is entailed in having it.

The problem we create in working from the abstract to the concrete is that we give students the impression that the orderterm and definition first, meaning second-reflects a conceptual hierarchy-in which the term matters but the meaning does notrather than a (flawed) pedagogical strategy. With that impression in mind, students are apt to focus on the definition and, because they may not quite grasp its meaning, zone out for the discussion of what justice (or any concept) is-the part of the class that really matters. To the students, the choice makes sense, since they perceive the term and the definition to be the important points. 


\section{THEORETICAL CONSIDERATIONS}

The argument that it is better to teach from the concrete to the abstract is hardly novel. This general insight lies at the root of well-known teaching techniques such as problem-based learning, situated learning, and the case study method. I shall not here revisit the vast and well-established literature that defenders of these techniques have produced. I do wish, however, to consider in greater detail the theoretical considerations surrounding my two central claims: first, that the concrete provides a useful motivational introduction to the abstract, and second, that it is a useful conceptual introduction (in contrast to its more common use as a vehicle to illuminate a previously provided abstraction). ${ }^{7}$

\section{The Motivation Claim}

To say that the concrete provides a useful motivational introduction to the abstract is to say that students are more motivated to learn when they can connect the subject matter with aspects of their own lives. This connection is, after all, what makes an idea concretethe concrete is that which exists in a manner that we experience. Motivation might be the direct result of a heightened interest"curiosity and arousal" (Keller 1983, 398) - that is generated from the familiar, ${ }^{8}$ the personal connection the familiar is apt to forge, 9 or simply the "enhanced meaning" of "learning experiences that include students' perspectives and values" (Wlodkowski 1999, 11). ${ }^{10}$ The common thread running through such ideas is that, as MacKinnon reports in the context of problem-based learning, "if students do not perceive the relevance of the content, they may be less inclined to complete their work" $(1999,56)$.

Additionally, the concrete can motivate students simply by presenting them with material that they can readily grasp and thereby giving them reasons to believe that success is likely. ${ }^{11}$ Here, the link between motivation and academic performance is particularly strong (Forsyth and McMillan 1991; Paulsen and Feldman 1999; Keller 1983). As Forsyth and McMillan remark,

Virtually all theories of human motivation argue that individuals intuitively calculate the probability that they will succeed in a particular situation.... Merely expecting success in no way ensures success, but a positive expectation about performance is a crucial link in the motivation-achievement chain..$^{12}(1991,57-58)$

Most of the implications drawn from this observation have centered on steps that instructors can take to convey positive expectations, but if students can convey such expectations to themselves via their own awareness that they can speak to issues relevant to their lives, so much the better.

There are two important points here that are opposite sides of the same coin. First, motivation is promoted when students perceive outcomes to be within their control. Second, what I have dubbed cognitive paralysis-commonly referred to as "learned hopelessness" (cf. Dweck and Reppucci 1973)-leads to a distinct lack of motivation and, of course, learning. ${ }^{13}$ In our justice example, students had control over the conversation's content and pace. Hence, even in the worst-case scenario-if the conversation failed to capture their interest-it is unlikely that they would succumb to a motivationally debilitating conceptual fog.

\section{The Conceptual Claim}

To some extent, it is difficult to argue against the claim that the concrete is a useful conceptual introduction to the abstract. Such a claim borders on being a truism: because the concrete is easier to grasp than the abstract, its logical place is at the beginning of understanding rather than the end. What is less self-evident is that the concrete-to-abstract order facilitates not only understanding, but also understanding of a high order (which can, in turn, promote student motivation ${ }^{14}$ ).

To see this point, let us consider how the traffic story could possibly be extended. After coming to grips with the idea that "differential treatment before the law is only justifiable when the differences between people are morally salient to the law," students might raise the issue of how moral salience is to be determined. In thinking about this issue, let us suppose that the conversation moves from the apprehension of speeders to punishment of them. In this scenario, students might ask whether differences in people's income or wealth are salient. Another way to frame that question would be to ask what it might mean for like cases to be treated similarly: Does similar treatment require fines that impose equal burdens, thereby setting fines that are proportionate to an individual's income, or does equal treatment require equal fines, irrespective of people's ability to pay them?

This discussion could easily spark an interesting debate. Although students might not come away with a sense of what a just fine would be, they will certainly glean an understanding of why and how arguments on either side are both claims about justice. In so doing, they will begin to see how to apply knowledge of a concept to different situations (or at least see how such knowledge is applied). The importance of this step cannot be underestimated. To understand that Rawls, in arguing for certain redistributive measures, and Nozick, in arguing against them, are both making claims about justice, despite the vast normative terrain that divides them, demonstrates a far subtler understanding of justice than that which is captured in the more abstract idea of "treating like cases similarly." It is one thing to grasp this abstract idea as an abstraction; it is quite another to see how that abstraction might lead to such different normative interpretations. But because students will have arrived at the abstraction via those interpretations, they come to understand it as something beyond any one interpretation-something that applies across cases-and thus the task of seeing what connects seemingly disparate cases should pose no added difficulty. ${ }^{15}$ (We presume that Cephalus and Polemarchus could not apply justice in instances for which no debts were owed or promises made, because in perceiving justice as only related to debts and promises, they would have no tools with which to approach unlike cases, such as the distribution of income.)

This ability to "apply" concepts has long been established as a more advanced learning objective. Two well-known theories are instructive on this point. The first is Bloom's classification (1956) of learning objectives. At the initial level of learning is the ability to name and define a concept. ${ }^{16}$ Here, students possess only the most rudimentary levels of "comprehension" that are "not made synonymous with complete understanding or even with the fullest grasp of a message" (1956, 89). This initial stage is important, but it is no more than a basic requirement for the sort of understanding that goes to the heart of any disciplinary study. Bloom's subsequent levels of learning-application, analysis, and synthesis-allow us to arrive at that understanding. At these levels, students can go beyond an understanding of, say, Rousseau's conception of democracy; here, they can also see the ways in which that conception is radically at odds with what, say, Schumpeter argued 200 years later. Finally, for students to 
make their own judgments about democracy-Bloom's highest level, "evaluation" 17 -they need to both use and move beyond this ability to apply, analyze, and/or synthesize.

As the discussion of speeding fines suggests, starting with the concrete allows us to engage and promote levels of understanding that go well beyond the basics. We have seen how students became engaged in the "application" of knowledge, but I would suggest that they went beyond even this level. In grappling with which fining principle makes sense, students came to understand not only that justice claims differ, but also that some claims are more persuasive to them than others. In other words, students engaged in a discussion that involved the analysis, synthesis, and evaluation of a concept to which they had only just been introduced (and perhaps could not even name yet!).

Another classic lens through which to view the level of student engagement is that of William Perry (1981). Perry argues that students consistently pass through recognizable levels of learning and knowing in the course of their "educational journeys." Perry describes nine such levels, with the broad development moving from "received knowing" (the unquestioned and absolute acceptance of an authority figure's claims) through "subjective knowing" (various forms of relativism) and on to "committed knowing," ${ }^{8}$ which he describes as "the capacity for metathought, for comparing the assumptions and processes of different ways of thinking" $(1981,85)$. The important point for the present purposes is that received and subjective knowing are emphatically not the intellectual endpoints of learning. That distinction belongs to a way of knowing in which one thinks for oneself and what one thinks is not that any idea is as good as any other.

My suggestion here is that at least an inchoate level of metathought is possible at the outset of learning, and that an early introduction to this more sophisticated way of knowing, which avoids climbing through names and definitions, provides students with an easier path to navigate, thereby increasing the odds that they will indeed become "committed" knowers. Students can understand-at the highest levels-a concept before they can name or define it; indeed, the context in which we apply, analyze, synthesize, and evaluate may make more sense if one is not burdened with the definition beforehand. Thus, both ends of the spectrum benefit from the top-down approach: not only do definitions make more sense within a context, but the context is itself rich in higherlevel learning. Speaking in more general epistemological terms, Dewey perhaps puts it best:

Any subject is cultural in the degree in which it is apprehended in its widest possible range of meanings. Perception of meanings depends upon perception of connections, of context. To see a scientific fact or law in its human as well as in its physical and technical context is to enlarge its significance and give it increased cultural value. (1922, 336)

\section{A FINAL THOUGHT}

There is one other important element of the concrete-to-abstract method that bears mentioning, one that goes to the heart of the Socratic ideal. At his trial, Socrates famously stated he had "never been anyone's teacher" and that "if anyone says that he has learned anything from me ... be assured that he is not telling the truth" (Plato 1981, 33a-b). Indeed, in certain Platonic dialogues, Socrates poses questions without a hidden answer in mind; that is, he seems eager for the conversation to go wherever he and his interlocutors take it. In this sense, perhaps, his interlocutors do not "learn anything from him." In other dialogues, the openendedness is less apparent, as Socrates seems to know the point at which he wants the conversation to arrive. ${ }^{19}$ What is true in both cases, however, is that the discussion, whether guided or not, eventually manages to transform the original inquiry. Even where Socrates has an end in mind, the discussion serves to show the interlocutors-and the reader-how ideas change in the course of thinking and discussing.

In the example of the Republic Book I, this change is clear. What begins as a discussion of what justice is ultimately becomes a discussion not just of that issue, but also of whether it is good to be just-or, as the issue is later put, of whether justice "is a kind of good we like for its own sake and also for the sake of what comes from it" (Plato 2004, 357b). ${ }^{20}$ Moreover, Plato demonstrates in the process that the second question is integral to the first. Thus, while readers may be no closer to understanding substantively what justice is, by the end of Book I, they have a transformed sense of what it means to ask the question.

Whether or not Socrates has an endpoint in mind, then, the central point remains: the act of teaching changes that which we teach. Outside of scripted dialogues, most of us do not, and, I would submit, cannot, fully know where our teaching will lead us. This is as it should be: learning is at its best when no oneincluding those who teach-is left out of the process. ${ }^{21}$ When we begin with an answer-the abstraction and its definition-we have no place to go, as whatever follows is somehow anchored by our initial understanding. Justice remains what we (or Wikipedia) say it is. When we begin with the concrete, however, we may not end up where we had anticipated ending up. Even when we arrive at the word and definition that we had in mind at the outset, our understanding of that word and definition will have been altered in some manner by the discussion that got us there. In the previous example, we no doubt anticipated that by the end of class, justice would be seen as treating people according to the morally relevant facts we know about them. What we could not have anticipated, however, is how the process of arriving at that understanding would shape the perspective we have upon it. If there is a beauty to education, it is surely that.

\section{NOTES}

I thank Harry Dangel, Tim O'Keefe, the Political Theory panel at the 2010 American Political Science Association Teaching and Learning Conference, and the anonymous reviewers of PS for their constructive feedback on earlier drafts of this article.

1. As Rousseau says: "To arrive [at abstract notions of philosophy and purely intellectual ideas] we must either separate ourselves from the body-to which we are so strongly attached-or make a gradual and slow climb from object to object, or, finally, clear the gap rapidly and almost at a leap, by a giant step upward of which childhood is not capable and for which men need many rungs especially made for them" $(1979,255)$.

2. To be more precise, Socrates sees that they conceive justice as particular acts. Neither realizes this fact until Socrates demonstrates that their conceptions lead to unacceptable conclusions. (I am indebted to Tim O'Keefe for suggesting I clarify this point.)

3. Whether or not Plato had such insights in mind is a separate matter that I do not address here.

4. This negative effect of definitions was anecdotally confirmed by my daughter, who came to me one day and asked what "exacerbate" meant. I said "it means to make worse ... like when you scratch poison ivy, you exacerbate it." She replied, "You mean, like, to make worse?" Here, it was not that my definition ("to make worse") bored her or went over her head, but it was as if she had some sort of internal mechanism that prevented her from even hearing it. 
5. As noted earlier, the definitions of Cephalus and Polemarchus are offered as abstractions. Upon reflection, however, neither is accepted as such (see note 2).

6. It may, of course, be useful to begin an exploration of a concept by seeing how students already use it and/or understand or misunderstand it. I do not discuss that technique here.

7. Although I do not directly address a third claim that comprehension and motivation are mutually reinforcing, much of what I explore here touches on this idea.

8. Forsyth and McMillan note that "novel, challenging, or unfamiliar ideas are more interesting to learners when they are tied to more familiar, personally relevant ideas" $(1991,62)$

9. Brophy contends that "teachers can promote personal identification with the content by relating experiences of telling anecdotes illustrating how the content applies to the lives of particular individuals" $(1987,197)$.

10. Wlodkowski $(1999,11)$ discusses enhanced meaning as one of "four intersecting motivational conditions that teachers and students can create or enhance." Another condition, named "developing attitude" and defined as "creating a favorable disposition toward the learning experience through personal relevance and choice," also produces the motivation benefits of the concrete.

11. Keller argues that such "expectancy" is one of the "four basic categories of motivational conditions" $(1983,395)$.

12. Forsyth and McMillan date the origin of this thinking to Tolman (1955).

13. Paulsen and Feldman (1999) argue along similar lines with regard to student "self-efficacy."

14. Donald observes that "research suggests that students' deep motivation and strategies for learning are associated with higher-order learning" (1999, 28). See also Forsyth and McMillan $(1991,55)$.

15. A parallel case appears in looking at language acquisition. By repeatedly hearing a word in a foreign language, we eventually come to understand its meaning because we hear the commonality that exists in the different contexts in which it is uttered. Of course, we could just look the word up, but that would provide us only with an abstraction that may or may not bring to mind the contexts that bring meaning to the word. We would know the word, but not the concept-or, in a sense, we would know the word, but not its meaning. If, however, we came to understand the word from actual uses of it, we might not be able to formulate a good definition of it, but we would know it in the deeper sense of being able to actually use it (apply it) in a variety of contexts. Similarly, to see that Rawls' difference principle and Nozick's entitlement theory both speak to a similar type of concern is to get at the heart of that concern in a manner that a definition simply would not.

16. The overview provided here is far from comprehensive. In the interest of brevity, I have glossed over much detail. For a good schematic overview, see Anderson and Krathwohl (2001).

17. Updated versions of this taxonomy add the higher level of "creation" (Anderson and Krathwohl 2001, 28)

18. Alternatively, the nine stages are often clustered into four levels: dualism, multiplicity, relativism, and commitment within relativism. See Hofer and Pintrich $(1997,91)$

19. The contrast between these two methods of dialogue can be seen clearly in the shift from the chaos of the Republic Book I to the systematic questioning of the Republic Books II-X.
20. I am indebted to discussants at the 2010 American Political Science Association Teaching and Learning Conference, particularly Murray Dry and James Stoner, for raising this point.

21. Freire's pedagogical ideal captures the thought well: "The teacher is no longer merely the-one-who-teaches, but one who is himself taught in dialogue with the students, who in turn while being taught also teach. They become jointly responsible for a process in which all grow" $(1988,67)$

\section{REFERENCES}

Anderson, L., and D. Krathwohl. 2001. Taxonomy for Teaching, Learning, and Assessing: A Revision of Bloom's Taxonomy of Educational Objectives. New York: Longman.

Aristotle. 1999. Nicomachean Ethics. Trans. T. Irwin. Indianapolis: Hackett.

Bloom, B. 1956. Taxonomy of Educational Objectives: The Classification of Educational Goals. New York: Longman.

Brophy, J. 1987. “Socializing Students' Motivation to Learn.” In Advances in Motivation and Achievement, vol. 5, ed. M. Maehr and D. Kleiber, 181-210. Greenwich, CT: JAI Press.

Dewey, John. 1922. Democracy and Education: An Introduction to the Philosophy or Education. New York: MacMillan.

Donald, J. 1999. "Motivation for Higher-Order Learning." New Directions for Teaching and Learning 78: 27-35

Dweck, C., and N. Reppucci. 1973. "Learned Helplessness and Reinforcement Re sponsibility in Children." Journal of Personality and Social Psychology 25 (1): 109-16.

Forsyth, D. R., and J. H. McMillan. 1991. "Practical Proposals for Motivating Students." In College Teaching: From Theory to Practice, ed. R. J. Menges and M. D. Svinicki. New Directions for Teaching and Learning 45: 53-65. San Francisco: Jossey Bass.

Freire, Paulo. 1988. Pedagogy of the Oppressed. New York: Continuum.

Hofer, B., and P. Pintrich. 1997. "The Development of Epistemological Theories: Beliefs about Knowledge and Knowing and Their Relation to Learning." Review of Educational Research 67 (1): 88-140.

Keller, J. 1983. “Motivational Design of Instruction.” In Instructional-Design Theories and Models: An Overview of their Current Status, ed. C. Reigeluth, 383-434. Hillsdale, NJ: Erlbaum.

MacKinnon, M. 1999. "CORE Elements of Student Motivation in Problem-Based Learning." New Directions for Teaching and Learning 78: 49-58.

Paulsen, M., and K. Feldman. 1999. "Student Motivation and Epistemological Beliefs." New Directions for Teaching and Learning 78: 17-25.

Perry, W. 1981. "Cognitive and Ethical Growth: The Making of Meaning." In The Modern American College: Responding to the New Realities of Diverse Students and a Changing Society, ed. A. Chickering and Associates, 76-116. San Francisco: Jossey-Bass.

Plato. 1981. Apology: In Five Dialogues. Trans. G. M. A. Grube. Indianapolis: Hackett.

. 2004. The Republic. Trans. C. D. C. Reeve. Indianapolis: Hackett.

Rousseau, J. J. 1979. Emile, or On Education. Trans. A. Bloom. New York: Basic.

Tolman, E. C. 1955. "Principles of Performance." Psychological Review 62: 315-26.

Wlodkowski, R. 1999. "Motivation and Diversity: A Framework for Teaching." New Directions for Teaching and Learning 78: 7-16. 